University of Wollongong

Research Online

Faculty of Social Sciences - Papers (Archive) Faculty of Arts, Social Sciences \& Humanities

2013

Wildfire preparedness, community cohesion and social-ecological systems

Tim Prior

Eth Zurich

Christine Eriksen

University of Wollongong, ceriksen@uow.edu.au

Follow this and additional works at: https://ro.uow.edu.au/sspapers

Part of the Education Commons, and the Social and Behavioral Sciences Commons

Research Online is the open access institutional repository for the University of Wollongong. For further information contact the UOW Library: research-pubs@uow.edu.au 


\title{
Wildfire preparedness, community cohesion and social-ecological systems
}

\begin{abstract}
The consequences of wildfires are felt in susceptible communities around the globe on an annual basis. Climate change predictions in places like the south-east of Australia and western United States suggest that wildfires may become more frequent and more intense with global climate change. Compounding this issue is progressive urban development at the peri-urban fringe (wildland-urban interface), where continued infrastructure development and demographic changes are likely to expose more people and property to this potentially disastrous natural hazard. Preparing well in advance of the wildfire season is seen as a fundamental behaviour that can both reduce community wildfire vulnerability and increase hazard resilience - it is an important element of adaptive capacity that allows people to coexist with the hazardous environment in which they live. We use household interviews and surveys to build and test a substantive model that illustrates how social cohesion influences the decision to prepare for wildfire. We demonstrate that social cohesion, particularly community characteristics like 'sense of community' and 'collective problem solving', are community-based resources that support both the adoption of mechanical preparations, and the development of cognitive abilities and capacities that reduce vulnerability and enhance resilience to wildfire. We use the results of this work to highlight opportunities to transfer techniques and approaches from natural hazards research to climate change adaptation research to explore how the impacts attributed to the social components of social-ecological systems can be mitigated more effectively.
\end{abstract}

\section{Keywords}

social, ecological, systems, wildfire, preparedness, community, cohesion

\section{Disciplines}

Education | Social and Behavioral Sciences

\section{Publication Details}

Prior, T. \& Eriksen, C. (2013). Wildfire preparedness, community cohesion and social-ecological systems. Global Environmental Change, 23 (6), 1575-1586. 
Prior, T. \& Eriksen, C. 2013. "Wildfire preparedness, community cohesion and social-ecological systems." Global Environmental Change, Available online 31 October 2013.

http://dx.doi.org/10.1016/j.gloenvcha.2013.09.016.

\section{Wildfire preparedness, community cohesion and social-ecological systems}

\section{Abstract}

The consequences of wildfires are felt in susceptible communities around the globe on an annual basis. Climate change predictions in places like the south-east of Australia and western United States suggest that wildfires may become more frequent and more intense with global climate change. Compounding this issue is progressive urban development at the peri-urban fringe (wildland-urban interface), where continued infrastructure development and demographic changes are likely to expose more people and property to this potentially disastrous natural hazard. Preparing well in advance of the wildfire season is seen as a fundamental behaviour that can both reduce community wildfire vulnerability and increase hazard resilience - it is an important element of adaptive capacity that allows people to coexist with the hazardous environment in which they live. We use household interviews and surveys to build and test a substantive model that illustrates how social cohesion influences the decision to prepare for wildfire. We demonstrate that social cohesion, particularly community characteristics like 'sense of community' and 'collective problem solving', are community-based resources that support both the adoption of mechanical preparations, and the development of cognitive abilities and capacities that reduce vulnerability and enhance resilience to wildfire. We use the results of this work to highlight opportunities to transfer techniques and approaches from natural hazards research to climate change adaptation research to explore how the impacts attributed to the social components of social-ecological systems can be mitigated more effectively.

Keywords: wildfire, preparedness, community cohesion, resilience, social-ecological system

Word count: 8316

\section{Introduction}

Fire in the landscape is a natural phenomenon in many regions of the world, supporting both ecological processes and cultural practices. Yet the 'naturalness' of this phenomenon is simultaneously in a state of flux and controversial due to global climate change and population expansion into naturally vegetated landscapes. Global climate predictions suggest that wildfires will become more intense and more frequent, particularly in south-east Australia and in parts of the western United States (Bradstock et al., 2009; Hennessy et al., 2005; Lucas et al., 2007; McKenzie et al., 2004). Even if these predictions turn out to be inaccurate, the structural and demographic changes and developments at the 'peri-urban fringe' (interface landscapes characterised by a mix of urban, rural and wildland features: see Stewart et al., 2007; Buxton et al., 2006) will increase the consequence of wildfires in the future. 'Wildfire' has become an accepted moniker for danger, reflecting the growing hazardousness and potential for disaster of an endemic force in many ecosystems.

What makes wildfires disastrous is their social impact. Yet many wildfire studies have historically overlooked this social element, instead being framed within ecology or environmental research. More recent scholarship has focused on understanding the human dimensions of wildfire management and mitigation, demonstrating 
Prior, T. \& Eriksen, C. 2013. "Wildfire preparedness, community cohesion and social-ecological systems." Global Environmental Change, Available online 31 October 2013.

http://dx.doi.org/10.1016/j.gloenvcha.2013.09.016.

that the solutions are often social, not just engineered or environmental (Bihari and Ryan, 2012; Brenkert-

Smith et al., 2006; Collins, 2009; Cottrell, 2005; Eriksen and Gill, 2010; McCaffrey et al., 2013; McCaffrey et al., 2011; Paveglio et al., 2011; Sturtevant and McCaffrey, 2007). An important aspect of this human dimensions work has been an exploration of the role (and responsibility) of community members in mitigating their own wildfire risk. Here wildfire preparedness is advocated as an important means by which individuals and communities can reduce vulnerability and increase resilience to wildfire. While the relationship between preparation, vulnerability and resilience is yet to be fully understood (and may not be interchangeable as much of the disaster literature infers), results from preparation research across a range of natural hazards alludes to their strong connection and interaction, demonstrating that preparing minimises the consequences of the hazard and increases the ability of people to cope with, recover from and adapt to the hazard (Jonientz-Trisler et al., 2005; Lindell and Perry, 2000; Paton et al., 2008; Thomalla et al., 2006; Whittaker et al., 2012). Preparing enables at-risk people to coexist more sustainably with hazardous environments (Paton, 2006).

A central issue for wildfire managers is therefore the ability to understand the social processes that influence this complex social-ecological system. This paper uses qualitative and quantitative techniques to model the interactions between several key social factors that influence wildfire preparation. Many of these factors have been individually demonstrated as important determinants of disaster mitigation. Yet little systematic work has to date specifically identified how they relate to each other and what these relationships mean for wildfire vulnerability and resilience. That is, what social factors influence the ability of people to mitigate or adapt to the threat posed by natural hazards like wildfire, and how is the interaction between these factors important? Drawing on an Australian case study, the paper highlights the importance of social cohesion and social connections in preparation. It builds on advances in research on the human dimensions of natural hazards and disasters to illustrate how a focus on people in the environment may help to inform more effective responses to socially driven environmental issues associated with climate change. Like Adger (2003), we argue that community resilience springs from factors connected to the cohesive community. We explore causal relationships between social factors that influence individual and community-scale decision-making in relation to wildfire preparedness. People are shown to rely on this cohesion as a resource that supports both the adoption of mechanical preparations, and the development of cognitive abilities and capacities that can reduce vulnerability and contribute to resilience. We use the results of this work to examine the similarities and differences between natural hazards research and studies of climate change science. The paper suggests opportunities to transfer techniques and advances from natural hazards research to climate change science to explore how the impacts attributed to the social components of social-ecological systems can be mitigated more effectively.

\section{Background}

Natural hazards have long posed challenges for the communities that inhabit the places hazards affect. In all cases, the social impact can be gauged in lives, lifestyles and livelihoods lost or disrupted, not to mention the property and infrastructure destroyed. Indeed, what converts these naturally occurring hazards into disasters is their interaction with people. Equally important in this context is the makeup of society, and the ability of the 
Prior, T. \& Eriksen, C. 2013. "Wildfire preparedness, community cohesion and social-ecological systems." Global Environmental Change, Available online 31 October 2013.

http://dx.doi.org/10.1016/j.gloenvcha.2013.09.016.

members and components of society (individuals, neighbourhoods, communities, social structures and institutions) to mitigate and successfully adapt to impending risks.

Recent events such as the 'Black Saturday' wildfires in Victoria, Australia (2009), hurricane 'Katrina' in New Orleans, USA (2005), earthquakes in Haiti (2010) and New Zealand (2011), and the South East Asian and Japanese tsunamis (2004 and 2011 respectively) provide all-too-real indications of the ferocity and disastrous potential of the interaction between natural hazards and society. Such hazard activity also highlights the need for society to develop or refine the mechanisms that are used to confront these hazards - whether behavioural, cultural, structural or institutional.

In this paper we consider the way social cohesion influences knowledge about preparation, and the propensity to prepare for wildfire. We draw on this relationship to explore how preparation contributes to the adaptive capacity of people who are part of the wildfire social-ecological system, drawing on a broad base of disaster studies research to support the work. In the context of wildfire as a natural hazard, the concepts of vulnerability, resilience, and adaptive capacity are closely connected to wildfire preparation. Preparation can reduce vulnerability and increase resilience. Yet, the relationship between vulnerability and resilience is not always straightforward, and not always interchangeable. For example, undertaking wildfire preparations (with the aim of staying and defending a property or reducing hazardous fuels, etc.) can reduce vulnerability to a wildfire, but these actions may not automatically confer resilience. For instance, a person or community may be resilient because of their personal/collective abilities, not because of the structural modifications they make to their properties. We suggest that preparing for wildfire is part of an adaptation strategy that contributes to individual and collective hazard adaptive capacities.

\subsection{Wildfire as a social-ecological system}

The 'social-ecological system' (SES) concept has been used to represent the complex associations of people and nature. It connects people and their communities to the places they live and the impacts they have on those environments (Gallopín, 2006; Walker et al., 2004; Westley et al., 2002). SES has become a fundamental unit of focus in the climate change literature, where acknowledging an explicit connection between social and ecological systems is seen as imperative in generating effective solutions to intractable (even 'wicked') problems resulting from interactions between environment and society. However, connecting examinations of environment and society seamlessly remains a challenging research goal, but one that may be informed by a greater understanding of the specific social processes that influence peoples' interactions with the environment.

Environmental and ecological processes impact on people, just as human behaviour impacts on nature. Natural hazards like wildfire flip the focus in social-ecological systems from concern about the environment and the disruption of ecological processes wrought by human activity, to concern for the communities and the social disruption caused by natural processes. While this focus might be a mirror image of traditional SES research, communities at risk from or impacted by wildfire also represent the social dimension of a social-ecological system. Furthermore, the theoretical advances made in SES research in the climate change sciences in the last 
Prior, T. \& Eriksen, C. 2013. "Wildfire preparedness, community cohesion and social-ecological systems." Global Environmental Change, Available online 31 October 2013.

http://dx.doi.org/10.1016/j.gloenvcha.2013.09.016.

108

109

110

111

112

113

114

115

116

117

118

119

120

121

122

123

124

125

126

127

128

129

130

131

132

133

134

135

136

137

138

139

140

141

142

143

144

decade directly mirror human dimensions of natural hazards research. The synergies between these two research disciplines are close, and concepts like vulnerability, adaptive capacity and resilience are already imbued with significant cross-disciplinary relevance. Resilience and vulnerability, for example, have become key terms in the language of risk and environmental management. Both terms are used widely to denote general states of an entity - this community is 'resilient' to wildfire; that ecosystem is 'vulnerable' to climate change; the individual's 'resilience' has fallen, etc. Yet, while these terms have become part of both the SES and disaster studies vernaculars, their actual meanings often vary as much as the uses to which they are put and the sub-disciplinary contexts within which they are used.

Arguments for and against conceptual vagueness can easily be made (Strunz, 2012), but it is increasingly evident that the obscurity of these terms is linked to their inherent complexity as concepts and the uncertain linkages between them (Folke, 2006; Haimes, 2009; Ungar, 2012; Walker and Cooper, 2011). Norris and colleagues (2008, p127), for example, examined community resilience in the context of disasters, framing it as a "process linking a network of adaptive capacities" to adaptation, readiness and response. They suggest resilience decreases aspects of vulnerability, while Berkes (2007, p. 284) suggests that vulnerability "resides" in the resilience of a system. Contrarily, Gallopín (2006) considers resilience to be related to 'capacity of response', a component of vulnerability and an internal property of the system. Adger (2006, p 268) classifies vulnerability as "susceptibility to harm", which can be influenced by elements of resilience like autonomous self-organisation, shock absorption and pre- and post-shock reaction. The notion of 'resilience elements' is loosely reflected in Norris et al.'s assertion that resilience is determined by a "set of adaptive capacities" (2008, p 136), and Smit and Wandel (2006) point out that vulnerabilty decreases as adaptive capacity increases. Paton (2006) frames resilience as the ability to coexist with a natural hazard - not in the sense of being able to return to normal or 'bouncing back' - but to adapt to the new life and reality that the disaster's consequences present. That many authors, across a range of disciplines, have given extensive theoretical treatment to the relationships between these concepts without yielding real clarity arguably highlights the need for further empirical examinations of real systems where the relationships between these conceptual features can be observed in action.

\subsection{Preparedness: an element of adaptive capacity}

Natural hazard preparation is generally considered to be the preferred mechanism to encourage proactive actions (behavioural, cultural, structural or institutional) to mitigate the disastrous potential of these events (CDRSS, 2006; UN/ISDR, 2004). Preparation has dual objectives: to reduce vulnerability to a potential threat (CDRSS, 2006; Grothmann and Reusswig, 2006; Siegrist and Gutscher, 2008; Thomalla et al., 2006; Whittaker et al., 2012), and to increase the resilience of the public exposed to a threat (Berkes, 2007; Cutter et al., 2008; Norris et al., 2008; Paton et al., 2006a; Tobin and Whiteford, 2002; Vermaak and van Niekerk, 2004). Both objectives can be achieved independently by promoting practical and psychological hazard preparedness, and this has become one of the key hazard mitigation goals of natural hazard management agencies. In the context of wildfire, preparedness can involve behavioural plans, structural improvements, and vegetation management actions, all of which can mitigate the level of risk faced by a property and improve residents' capacity to 
Prior, T. \& Eriksen, C. 2013. "Wildfire preparedness, community cohesion and social-ecological systems." Global Environmental Change, Available online 31 October 2013.

http://dx.doi.org/10.1016/j.gloenvcha.2013.09.016.

145

146

147

148

149

150

151

152

153

154

155

156

157

158

159

160

161

162

163

164

165

166

167

168

169

170

171

172

173

174

175

176

177

178

179

180

181

respond to a wildfire event. Table 2 provides a detailed list of wildfire preparations that are advocated by fire management agencies in Australia.

By decreasing vulnerability and increasing resilience, preparation can be considered an element of the social system's adaptive capacity - an adaptation that permits the individual, household or community to coexist with the potential threat and consequences of environmental hazards like wildfire (Paton, 2006). Adaptive capacity allows the social system "to evolve in order to accommodate environmental hazards... and to expand the range of variability with which it can cope" (Adger, 2006, p.270). Preparation helps to precondition at-risk societies to the changes natural hazards potentially bring, thus contributing to their adaptive capacity. This permits them to respond both proactively and reactively through social learning (Gallopín, 2006), and by drawing on threat(context) specific technical and cultural advances (Eriksen and Prior, 2011; Folke, 2006; Gallopín, 2006; Klein et al., 2003; Smit and Wandel, 2006). As Smit and Wandel (2006, p. 282) point out "adaptation in the context of human dimensions of global change usually refers to a process, action, or outcome in a system ...in order for the system to better cope with, manage or adjust to some changing condition, stress, hazard, risk or opportunity". As an adaptation, and element of adaptive capacity, preparation clearly falls within this characterisation, but as Klein et al. (2003, p 38) highlight, the "existence of adaptation options does not mean that each vulnerable community, sector, or country has access to these options or is in a position to implement them." The failure to implement these adaptations is a central point of discussion in both the disaster risk reduction and climate change discourses.

Social contacts, cohesion, collaboration and trust have been proven to be key motivators in hazard preparedness (Carroll et al., 2005; Lachapelle and McCool, 2012; Paton et al., 2008; Paveglio et al., 2011; Siegrist and Cvetkovich, 2000). Shinn and Toohey (2003, p. 427) even suggest that a failure to acknowledge the role of the community in forming the beliefs and attitudes of the individual "has adverse consequences for understanding psychological processes and efforts at social change". This view is broadly supported in the wider socio-psychological literature on resilience and vulnerability in trauma, risk and social responses to such processes (Bonanno, 2005; Norris et al., 2008; Ungar, 2012). In acknowledging this, recent hazard preparedness research has highlighted the necessity of engaging people and communities in risk communication and mitigation activities, rather than simply expecting them to respond to passive information cues or sources (Eriksen and Prior, 2011). Overlooking the complexity of the social interplay between, for example, individual community members or between local communities and the civil structures that develop policies designed to assist society, can significantly obstruct the success of any given initiative aimed at mitigating the social consequences of natural hazards.

Wildfire poses a threat to individuals, neighbourhoods and communities alike. However, wildfire preparation is generally undertaken by the household for the household, despite communal responses having significant hazard mitigation benefits for the community collectively. One household's lack of preparation may influence the severity of the neighbourhoods' experience of wildfire, principally because an unprepared property may become fuel that increases the risk of the fire spreading to neighbouring properties (Gibbons et al., 2012). Homeowners who share an interest in working together generally improve their overall level of preparedness 
Prior, T. \& Eriksen, C. 2013. "Wildfire preparedness, community cohesion and social-ecological systems." Global Environmental Change, Available online 31 October 2013.

http://dx.doi.org/10.1016/j.gloenvcha.2013.09.016.

182

183

184

185

186

187

188

189

190

191

192

193

194

195

196

197

198

199

200

201

202

203

204

205

206

207

208

209

210

211

212

213

214

215

216

217

218

and thus the likelihood of successfully defending their properties from wildfire. This community element of

wildfire preparedness is represented by several key social factors that existing research has identified as important in wildfire preparation: information sharing and shared learning (Brenkert-Smith, 2010; Eriksen and Prior, 2011; McCaffrey et al., 2011), trust (Lachapelle and McCool, 2012), collective efficacy, sense of community and social norms (Paton et al., 2008), and responsibility (McCaffrey et al., 2011; Paveglio et al., 2009; Winter and Fried, 2000). These social elements are broadly reflective of and determined by the context of individual communities.

Examining wildfire preparedness at the level of the community, through the lens of the individual and the social processes of influence, can provide important insights into how different community characteristics, dynamics and discourses influence the way wildfire risk is addressed in those communities (Brenkert-Smith et al., 2006, 2010). It also provides a lens through which individual decision making in response to unpredictable and uncertain environmental change can be observed and understood in the context of societal norms and traditions (Enarson 2012; Eriksen et al., 2010; McCaffrey et al., 2011; Paton et al., 2008). These social structures and interrelationships contribute to an individual's mental model (or "sense-making": Westley et al., 2002) as well as their local environmental knowledge of wildfire in the place where they live, both of which contribute to social learning and 'appropriate' responses to wildfire threat (Eriksen and Prior, 2011). However, it is equally plausible that the rapid turnover of property ownership in the peri-urban environment can erode local environmental knowledge. The effect of amenity migration can lead to an erosion of intra-community familiarity and trust, as well as the loss of local wildfire knowledge held by long-term residents, many of whom may be hesitant to interact with and share their knowledge with newcomers (Cocklin and Dibden, 2005;

Eriksen and Gill, 2010; Forrest and Kearns, 2001; Morrison, 2003).

The focus of natural hazards research has slowly moved away from the 'command and control' actions that largely rely on technology to control nature and wildfire, to a social focus that emphasises the role of human behaviour, values, attitudes and decisions in managing wildfire. This shift has partly been driven by a realisation among wildfire management agencies of the important role community members can play in managing and mitigating wildfire (AFAC, 2010; McCaffrey and Rhodes, 2009; McCaffrey et al., 2011; Steelman and Kunkel, 2004). This highlights the capacity for self-organisation by the social components of the SES. Tapping into this capacity effectively could yield valuable social advances in addressing issues of vulnerability and resilience to natural hazards. Even so, encouraging people to prepare, as the most notable social response to natural hazards, is fraught with difficulty that has not been addressed by the techniques that have dominated natural hazard risk education and communication to date (Eriksen and Prior, 2011; Handmer and Haynes, 2008; Paton et al., 2008).

In the following sections, we explore the notion of SES and the capacity for self-organisation by focusing on the social determinants that underpin decisions to prepare amongst communities members living at-risk from wildfire. We explicitly focus on the sub-components of social interactions (that may contribute to social capital like sense of community, belonging, trust, collective problem solving) and the interesting and pointed directions this may yield for innovative and effective solutions to social problems in social-ecological systems. 
Prior, T. \& Eriksen, C. 2013. "Wildfire preparedness, community cohesion and social-ecological systems." Global Environmental Change, Available online 31 October 2013. http://dx.doi.org/10.1016/j.gloenvcha.2013.09.016.

\section{Methodology and Results}

This paper presents the results of a mixed-methods research project, which utilised qualitative and quantitative techniques to explore and model factors that influenced the preparedness of householders living at-risk of wildfire in southeast Australia. Qualitative data were used to develop a substantive model that illustrated the influence of social processes or factors on wildfire preparedness behaviour role. Quantitative data was used to test (validate) this substantive model.

\subsection{Qualitative data collection}

Qualitative data were collected using semi-structured interviews with adult household members from locations where the quantitative survey component of the research would be undertaken (see section 3.3). Interviews lasted between 30 and 90 minutes and were transcribed verbatim. The total number of interviews conducted was determined by data saturation. Interviewing continued as long as new ideas, themes, attitudes or beliefs were encountered. Interviews were based on a ten-question interview schedule that explored general cues for wildfire preparedness decision making and action, (including friends, family, and significant others; media; risk communication practices and content; and what preparations were undertaken, or not, and why). The interviews specifically focussed on elucidating the social drivers of preparedness decision making, and how these drivers compared to traditional forms of risk communication (pamphlets, advertisements, websites, etc.) as cues to hazard mitigation decisions. The semi-structured nature of the interviews permitted an in-depth discussion of the benefits of direct contact and interaction with neighbours, particularly those who were trusted, or with particular knowledge of, or experience with wildfire in the locality where the interviewee lived.

In total, 36 interviews were carried out over the phone with consenting individuals. Seventeen pilot interviews were conducted with purposively sampled consenting adults surveyed (but not interviewed) by Paton et al. (2006b) in March and April 2006 (who used a comparable survey instrument to the current study), and the data from these interviews was analysed and used to develop the survey instrument deployed in the quantitative component of this research. A further 19 interviews were conducted during the southern hemisphere winters of 2007 and 2008, following the distribution of the survey. Survey respondents could volunteer to take part in a follow-up telephone interview by providing their contact details with their survey response. Assenting respondents were sampled purposively based on their reported levels of preparedness in order to discuss the social influences on decision-making and preparation cues at all engagement levels of the preparedness spectrum. Narrative analysis of both sets of interviews (pre- and post-survey) using NVivo 7.0 illustrated strong similarities across the locations of interviewees and levels of wildfire risk, with no obvious influence from the survey. A decision was therefore made to combine these data sets for the development of the substantive model (section 3.2).

Once aggregated, all 36 interviews were systematically analysed using a four-step grounded theory technique (see Strauss and Corbin 1990, 1998). Data was coded in NVivo 7.0 using open, axial and selective coding techniques to highlight key themes in the data. Data was then analysed to identify relationships between 
Prior, T. \& Eriksen, C. 2013. "Wildfire preparedness, community cohesion and social-ecological systems." Global Environmental Change, Available online 31 October 2013.

http://dx.doi.org/10.1016/j.gloenvcha.2013.09.016.

254

255

256

257

258

259

260

261

262

263

264

265

266

267

268

269

270

271

272

273

274

275

276

277

278

279

280

281

282

283

284

285

286

themes and thereby build concepts that reflected these relationships. Concepts were aggregated based on broad similarities in order to generate a substantive model that explained the influence of social and individual drivers on preparedness. Grounded theory is a constant comparative method of systematic qualitative data analysis that allows the researcher to create networks among the concepts that emerge from the data (Strauss and Corbin, 1998). The grounded theory analyses focussed on exploring the causal relationships between key themes identified during coding of the interviews. This included an examination of how a given theme was influenced by or impacted on other themes. The identification of causal relationships permitted the development of a substantive (uni-directional) model representing the influence of social and individual processes on decision-making for wildfire preparedness.

\subsection{Effects of community and individual drivers on preparedness behaviour}

A mix of community-level and individual cues influenced preparedness for wildfire amongst the research participants. Interview analysis revealed the importance of 'sense of community' (McMillan and Chavis, 1986) and collective problem solving in overall levels of wildfire preparedness. At the individual level 'action coping' (Bishop et al., 2000; Carver et al., 1989), 'self-efficacy' (Bandura, 1977; 1986) and 'negative outcome expectancy' (Paton et al., 2008), along with more operational and inhibitory issues like financial, time and emotional costs involved with preparing (Eriksen and Gill, 2010; Paton et al., 2008), were important in determining preparation.

'Sense of community' emerged from the interview data as a key driver of preparedness, with direct and indirect influence on interviewees' preparation behaviour. The measure of 'sense of community' used in the survey included items associated with peoples' connections to the place they lived and the people who lived around them. The factor analysis conducted on this measure reduced the items into two groups that strongly represented place and people attachment. Both aspects (people and place) of 'sense of community' were important for interviewees. The social cohesion that comes with strong sense of community enabled people to share the anxiety that is associated with both the known threat of wildfire and the unknown consequences of the hazard, as captured by the reflections of one interviewee:

Unless there's other people around me, I don't think I'd really want to necessarily [prepare, stay and defend] on my own. If there was more than one person helping me, then I would probably stay, but I don't know whether l'd want to do it on my own. (Female, Hobart)

Interviewees worried less when they knew of other people in their community with whom they could share their concern. Sense of community contributed dramatically to individuals' willingness and ability to prepare for and act in a threat situation. Knowing that others were likely to help in an emergency was reassuring because fear, worry and responsibility could then be shared among the community members, easing the burdens presented by each of these aspects, which in turn increases 'self-efficacy'. 
Prior, T. \& Eriksen, C. 2013. "Wildfire preparedness, community cohesion and social-ecological systems." Global Environmental Change, Available online 31 October 2013. http://dx.doi.org/10.1016/j.gloenvcha.2013.09.016. The fact that there was actually another human being on site made like about $90 \%$ difference to me. In fact if I had just one more person there I'd feel, I would have no qualms at all, I would stay and defend and know my preparations would work. (Female, Hobart)

You know everybody worries about [wildfires]; they want to pretend they don't, but they do ... so you discuss the equipment you could buy, or what you could do. Yeah [the community] is pretty good. (Male, Hobart)

Sense of community also contributed to peoples' abilities to sift through risk information, identifying pertinent and contextual resources or advice. This increased individuals' ability to 'solve' (mitigate) the wildfire threat to communal and private property, increasing their 'action coping' ability. Conversely, people living in communities where there was little interaction between neighbourhood members were less likely to convert cohesiveness into preparation actions. This was largely attributable to lack of belief in effectiveness of preparedness behaviour ('negative outcome expectancy') - a belief reinforced by sense of isolation in terms of lack of help to carry out physical work and an inability to contextualise and localise information about preparing. Where there was extensive community knowledge of wildfire and the importance of preparing (which was often connected to personal wildfire experience) there existed not only greater levels of preparation in the community, but greater confidence in those preparations.

Everyone in the street is really into fire awareness and we've got a telephone tree if there's a fire, and we've had a few meetings over the summer talking about how to be prepared and that sort of stuff. We get most information from our neighbours. (Female, Hobart)

I think I would at first sign [of fire], I think I'd be gone... simply because there isn't a gang of neighbours here who would all look after themselves, it doesn't happen in this day and age ... we don't even know our neighbours' names. We put ourselves out to try and speak to them, but people don't speak anymore. Even on the street here, people turn the other way. (Male, Hobart)

Householders without personal wildfire experience expressed a need for affirmation from their peers of the value of preparedness behaviour, rather than from fire service representatives whose information was often viewed as theoretical and untested locally. Interview participants valued information from their peers who they knew had personal experience, which could be put to good use locally in a collective manner.

[What made a difference] was basically a few guys in the street who are really enthusiastic about [preparing] and are ready to impart knowledge and have a look at our pumps and all that stuff. (Female, Hobart)

One guy in particular worries about [wildfires] all the time. Oh he's quite fretful about it but, you know, he's good with information and that's why he's formed the fire group so that everybody in [the] Lane is in it, and we have a meeting about once a month. (Male, Hobart) 
Prior, T. \& Eriksen, C. 2013. "Wildfire preparedness, community cohesion and social-ecological systems." Global Environmental Change, Available online 31 October 2013.

http://dx.doi.org/10.1016/j.gloenvcha.2013.09.016.

320

321

322

323

324

325

326

327

328

329

330

331

332

333

334

335

336

337

338

339

340

341

342

The relationship between these observed cues in the interview data formed the basis for the substantive (structural) model presented in Figure 1. This substantive model is consistent with the causal relationships of decision-making cues identified in the qualitative data, and illustrates householder cognition specifically relating to the social cues behind decisions about wildfire preparedness.

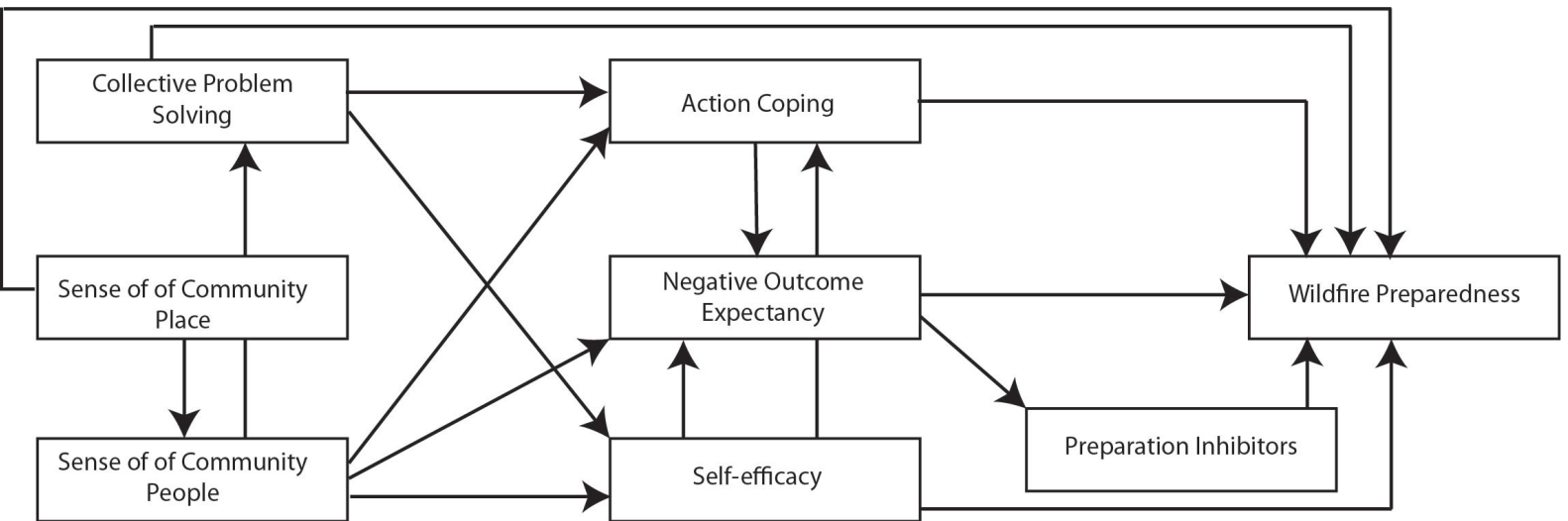

Figure 1. Substantive model of wildfire preparedness decision making derived from qualitative analysis of interviews conducted with householders living in peri-urban wildfire risk areas in Hobart.

As a substantive representation of the qualitative data, figure 1 highlights the importance of both sense of community of place and people, suggesting that attachment to the place where householders live and the people they associate with are the most formative elements in preparing for wildfire. Attachment to other community members (cohesiveness) influences the ability of that group to solve problems, and the effectiveness of those solutions (collective problem solving). These community level drivers influence individual level drivers of preparedness, including 'self-efficacy', 'action coping' and 'negative outcome expectancy', but also have a direct influence on wildfire preparedness. Self-efficacy describes an individual's capacity to act when threatened, and is improved in situations where community cohesiveness is strong. Action coping is a measure of an individual's problem solving beliefs (how capable they feel they are when dealing with problems in their lives) and is also influenced by sense of community and the community's collective problem solving capacities. Lastly, 'negative outcome expectancy' has a direct influence on wildfire preparedness. This relationship may also be negatively mediated by preparation inhibitors.

\subsection{Quantitative survey data collection}

Quantitative data was collected using a longitudinal survey distributed to households within 100 metres of bushland at the peri-urban fringe of Hobart (Tasmania) and Sydney (New South Wales), Australia. Surveys were distributed by hand early in the wildfire seasons (October) of 2006/07 and 2007/08. In 2006/07 1500 surveys were distributed in Hobart with 499 returned (33.2\% response rate). In 2007/08 1297 surveys were distributed in Hobart, and 1500 surveys were distributed in Sydney, with 399 returned in Hobart (30.7\% response rate) and 277 (18.5\% response rate) returned from Sydney. In both Hobart and Sydney, surveys were distributed to every house in selected streets that were within close proximity to bushland. These streets (and suburbs) were systematically targeted in order to ensure sampling locations had broadly similar levels of wildfire risk based on local wildfire risk mapping by the Tasmania Fire Service (Hobart), the New South Wales Rural Fire Service and 
Prior, T. \& Eriksen, C. 2013. "Wildfire preparedness, community cohesion and social-ecological systems." Global Environmental Change, Available online 31 October 2013.

http://dx.doi.org/10.1016/j.gloenvcha.2013.09.016.

349

350

351

352

353

354

355

356

357

358

359

360

361

362

363

364

365

366

367

368

369

370

371

372

373

374

375

376

377

378

379

380

381

382

383

384

the New South Wales Fire Brigade (now Fire and Rescue NSW) (Sydney). 'Broadly similar' wildfire risk means areas have similar vegetation types, levels of on-ground fuel and wildfire history.

The survey consisted of 38 questions covering a wide variety of issues known to influence wildfire preparedness based on established measures from the hazard preparedness literature (for example, Paton et al., 2008). Additional measures surveyed were identified and developed during the 17 pilot interviews conducted with consenting householders from the Hobart sampling region in March and April 2006. Structural equation modelling was used for model validation. This analysis technique is sensitive to missing values, so survey responses with a large proportion of unanswered questions were removed from the analysis data set. All remaining missing values were replaced with a regression estimate calculated in SPSS 16.0, and checked against hand calculations of the mean of the available item scores within a single measure (a more accurate, but time consuming approach to missing value replacement).

Exploratory factor analysis (maximum likelihood, oblique rotation) was used to examine the underlying structure of the survey measures and to confirm that items in one measure fell together as one factor. The suitability of the data for factor analysis was determined before examining analysis results (subject to item ratio exceeded 10:1). Only measures that exhibited more than one factor (with factor loadings between 0.5 and $0.9)$, and which could be explained as theoretically plausible with interpretable meanings were retained for possible analysis (Table 1). Following factor analysis the internal consistency (reliability) of possible factors to be included in the subsequent analyses were tested using the Chronbach's $\alpha$ (alpha) statistic. The alpha score generally increases as the correlations between items increase. Higher alpha scores for a set of items suggest those items measure similar characteristics and are considered to exhibit good internal consistency. Only measures with an alpha score close to or greater than 0.7 were included in further analysis (Table 1), as high reliability indicates the measure is replicable.

$<$ TABLE 1>

Table 1. Results of factor analysis and reliability testing of survey measures used in the structural equation modelling analysis. The measures for 'action coping' (Bishop, et al., 2000; Carver, et al., 1989), 'self efficacy' (Bandura, 1977; 1986) and 'preparation inhibitors' (Paton et al., 2008) did not reduce to more than one factor.

The wildfire preparedness of the survey respondents was measured using a 54-item measure (Paton et al., 2006; Paton et al., 2008). Factor analysis of the 54-item measure used in the survey reduced the set into three distinct factors (Table 2). One for preparation planning, which reflected individuals' deep thinking about wildfire threat, and the planning required to mitigate this threat. A second factor encompassed propertyrelated preparations, which included operational actions like clearing space around the property. The last factor encompassed items necessary for a wildfire-specific emergency kit. The first factor, preparation planning, is used here as the measure of household preparedness as it best reflects the difficulty and necessary consideration that preparing requires. Preparedness measure items could be answered by survey respondents in three ways: 'I have done this' (assigned a value of 3), 'I will do this' (assigned a value of 2), 'I will not do this' (assigned a value of 1). Reponses to the 'preparedness planning' factor (reduced from the 54-question 
Prior, T. \& Eriksen, C. 2013. "Wildfire preparedness, community cohesion and social-ecological systems." Global Environmental Change, Available online 31 October 2013. http://dx.doi.org/10.1016/j.gloenvcha.2013.09.016.

385

386

387

388

389

390

391

392

393

394

395

396

397

398

399

400

401

402

403

404

405

406

407

408

409

410

411

412

413

414 preparation measure) were tallied for an overall preparedness value for each survey respondent. As such, survey respondents who consistently indicated they 'have done this' preparation action scored more highly than those reporting they 'would not'. Self-report surveys often suffer from reporting bias, but the mixed methodology and purposive sampling techniques used in this study allowed the researchers to cross-check survey responses during the post-survey interviews. The 19 post-survey interviews were conducted with the interviewee's survey at hand, and the cross-check was conducted on several random survey questions during the interview when the discussion touched on issues directly explored in the survey. Contradictions between the survey response and the interviews were rare, but were noted as memos in the NVivo analysis where they occurred and considered in the analysis of the interviewee's information.

$<$ TABLE 2>

Table 2. Factor analysis of the 54-item preparedness list used in the survey reduced to three factors: preparedness planning, property preparedness, and wildfire emergency kit. The items in each factor are listed, but only the preparedness planning factor was used in analyses conducted here.

\subsection{Model validation}

The model developed from the qualitative interviews was validated against data from the appropriate survey constructs using structural equation modelling (SEM). SEM is a multivariate data analysis technique that combines aspects of multiple regression (structural path analysis) and factor analysis (measurement of latent constructs with multiple items) to estimate a series of interrelated dependence relationships (Kline, 2011). The model was built and validated using IBM SPSS v.19 with AMOS extension. SEM is particularly suited to this task because of its utility in confirming theory and its functionality for assessing causal relationships between variables that are based on qualitative assumption and analysis (Anderson and Gerbing, 1988; Byrne, 2001; Nachtigall et al., 2003). The benefit of using SEM lies in the ability to estimate multiple dependence relationships simultaneously and to identify how well empirical data fits with a hypothesised theory or substantive model (Goodness-of-fit).

Wildfire preparedness data collected from Hobart residents living at the peri-urban fringe in 2006/07 showed an excellent fit to the substantive model $(\mathrm{N}=482)$, with results summarised in Figure $2 \mathrm{a}$. The model accounted for $32 \%$ of the variance in preparedness planning, a good effect size in intention-behaviour relationships (Sheeran, 2002). Data collected from Hobart ( $N=349$, Figure $2 b$ ) and Sydney ( $N=221$, Figure 2c) in 2007/08 did not fit the proposed model as well and explained less of the variance in preparedness behaviour: $21 \%$ and $29 \%$ respectively. More detailed discussion and possible reasons for this poorer fit are given in section 4.1. 
Prior, T. \& Eriksen, C. 2013. "Wildfire preparedness, community cohesion and social-ecological systems." Global Environmental Change, Available online 31 October 2013.

2a)

http://dx.doi.org/10.1016/j.gloenvcha.2013.09.016.

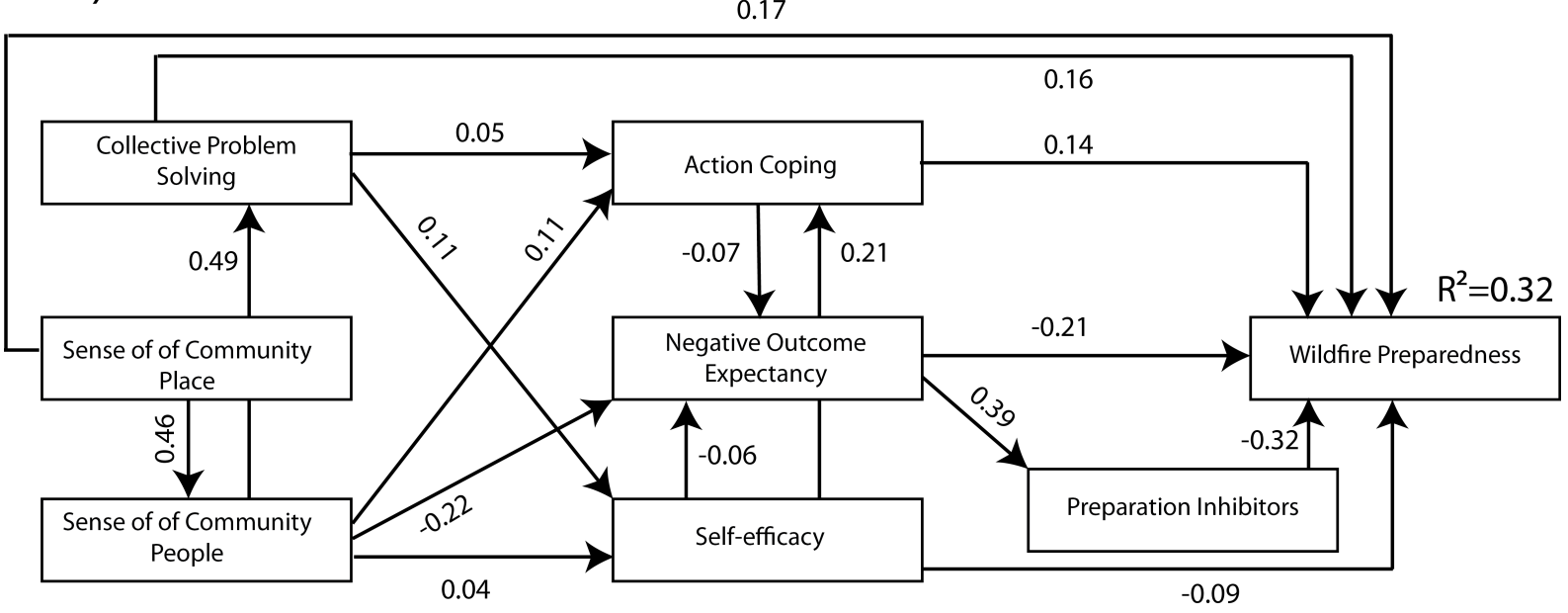

2 b)

0.11

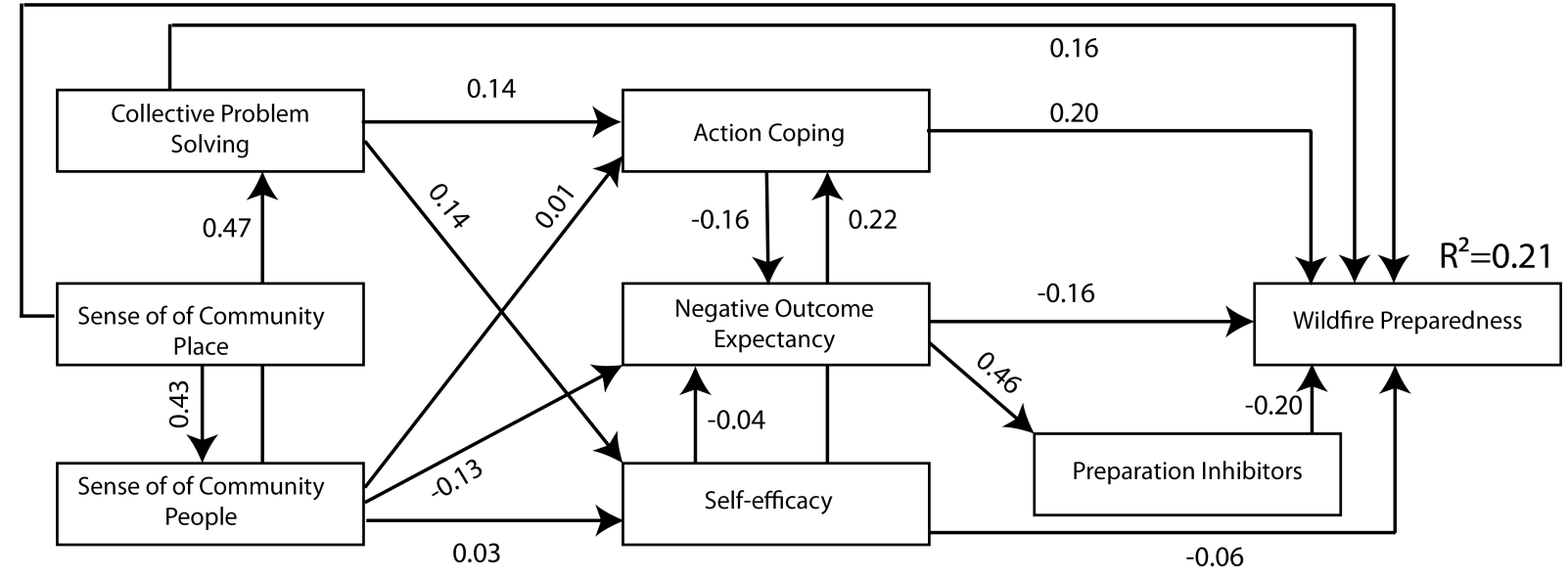

2c)

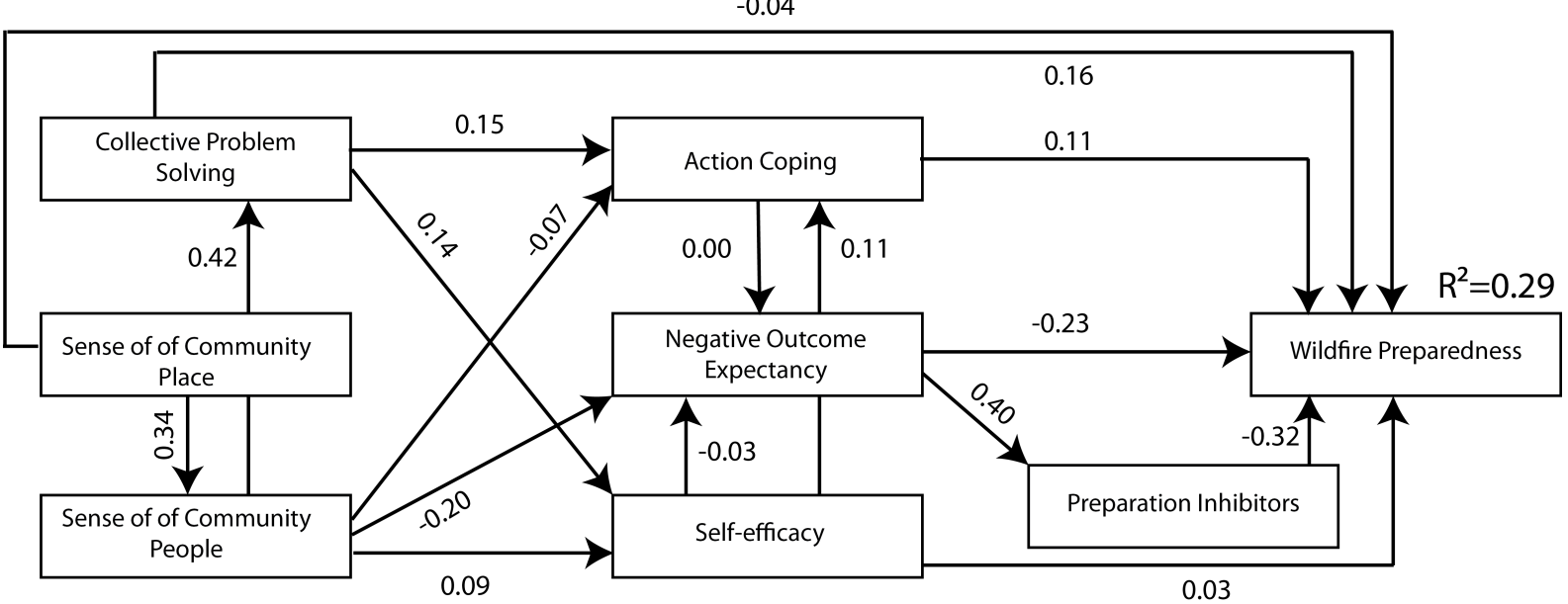

Figure 2. Measurement model $\left(a-\chi^{2}=8.291, d f=11, p=0.687\right.$; RMSEA $<0.001,90 \%$ confidence $\left.0.000-0.040\right)$ of

417 social cohesion in wildfire preparedness decision making using data collected from Hobart householders in

418 2007. Validation of measurement model using data collected in 2008 from households in Hobart (b - 
Prior, T. \& Eriksen, C. 2013. "Wildfire preparedness, community cohesion and social-ecological systems." Global Environmental Change, Available online 31 October 2013. http://dx.doi.org/10.1016/j.gloenvcha.2013.09.016.

419

420

421

422

423

424

425

426

427

428

429

430

431

432

433

434

435

436

437

438

439

440

441

442

443

444

445

446

447

$\chi^{2}=26.795, d f=11, p=0.005 ; R M S E A=0.064,90 \%$ confidence $\left.0.034-0.096\right)$ and Sydney $\left(c-\chi^{2}=25.796, d f=11, p=0\right.$ 007; RMSEA=0.079, 90\% confidence 0.039-0.119). Models show $R^{2}$ values for planning preparedness and standardised regression weights of paths.

\section{Discussion}

The results from this empirical study demonstrate that social processes, and particularly cohesive communities, contribute substantially to individual preparation and the adaptive capacity of communities and community members who are threatened by wildfire. In this context adaptive capacity is reflected in the uptake of preparation behaviours, both at the individual and community levels. Individuals or communities that do not adopt protective measures have less capacity to adapt to wildfire threat and consequences. In the following sections, we discuss why membership in cohesive communities promotes preparation, and why individuals living in non-cohesive communities are less likely to respond in the same way. We explore how a cohesive community contributes to reduced vulnerability and the development of community and individual resilience. We extend the findings from this study to broader work on social-ecological systems. We suggest that paying greater attention to social attitudes, beliefs, values and emotions concerning the environment, and how these are influenced, could inform more effective and lasting solutions to intractable environmental problems that are socially derived.

\subsection{Why social cohesion helps people prepare}

From the results presented in section 3 it is clear that individuals facing wildfire threat draw on a supportive community to build their individual adaptive capacities and translate these into community-wide adaptations. Furthermore, under-prepared people or those with little knowledge about wildfire mitigation clearly benefit greatly from close community associations. Social connections permit faster and more risk-appropriate reorganisation, change and learning around the threat of wildfire. Whilst most natural hazards can be anticipated to a degree, their irregularity results in many people being taken by surprise when they do occur. Even wildfire, which can be expected with more certainty and regularity than many other natural hazards because of the seasonal nature and close connection to weather, is unfamiliar to many people. This is particularly the case for people relocating from the city to amenity-rich, but wildfire-prone, landscapes for lifestyle reasons. People who face uncertain threats often rely on their peers, family or neighbours who they believe, or perceive, have better or more complete knowledge about the threat, how to anticipate it and how to respond. Knowledge about wildfire, and where that knowledge comes from, is crucial in forming a decision about whether and how to respond to the threat it poses (Eriksen and Prior, 2011).

The model presented in Figure 1 and validated in Figures 2a-2c highlights how thinking about wildfire preparedness as a decision-making process can help to illustrate the importance of social cohesion in preparing. Decision-making is plagued by uncertainty, which clouds rational decision-making (Basili, 2006; Donovan and Blake, 1992; Jones, 1999; Slovic et al., 2004). People often do not reach rational decisions as a result of their cognitive reasoning. This is partly due to the social construction of risk (Dake, 1992; Hannigan, 
Prior, T. \& Eriksen, C. 2013. "Wildfire preparedness, community cohesion and social-ecological systems." Global Environmental Change, Available online 31 October 2013. http://dx.doi.org/10.1016/j.gloenvcha.2013.09.016.

454

455

456

457

458

459

460

461

462

463

464

465

466

467

468

469

470

471

472

473

474

475

476

477

478

479

480

481

482

483

484

485

486

487

488

489

490

2006; Holstein and Miller, 2006; Lupton and Tulloch, 2002; Tierney, 1999), and partly because active cognition is undertaken with immediate information at hand and with subconscious deductions made to reach the most agreeable, but not necessarily the most rational outcome (Finucane et al., 2000; Loewenstein et al., 2001). Tversky and Kahneman $(1974,1981)$ showed that individuals rely heavily on affect heuristics (mental shortcuts often driven by emotions) to guide their judgement, enabling them to simplify otherwise difficult choices. But once the choice is simplified in this way, judgemental errors are likely to become more common (see also, Jones, 1999; Kahneman, 2003; Sjöberg, 1982). This plays a role even in choices familiar to the decision maker. However, in familiar circumstances individuals are likely to be able to better judge the possible outcomes and estimate how likely these are to occur, giving them some ability to choose and act 'advantageously' to avert risk (Bechara et al., 1997; Fox and Levav, 2000; Kahneman, 2003; Keller et al., 2006).

Sharing knowledge, support and advice are valuable community activities that allow people to contextualise irregular and uncertain threats in their daily lives. This information provides some vicarious familiarity to the uncertain decision-making context. In the case of wildfire, decisions about preparing and mitigating risk are enhanced by consultation and collaboration with others. Collective action is required to, for example, support hazard reduction or pile burns and to ensure that all households reduce the level of combustible materials in and around their properties. Attachment to place and engagement with other members of the community increase the likelihood that householders consider preparation to be important (Brenkert-Smith, 2011; Eriksen and Gill, 2010; Eriksen and Prior, 2011; Prior, 2010). Their interactions concerning wildfire preparedness increase their capacity to understand and address the uncertainty and the challenging nature of events like wildfire activity (Eng and Parker, 1994; Hardin and Higgins, 1996; Lion et al., 2002).

The story is very different in places where cohesive and supportive relationships between community members do not exist. This issue is illustrated in the validation exercise, which tested the results of the 2006/07 Hobart survey data (Figure 2a) against the 2007/08 survey data from communities in Hobart (Figure 2b) and Sydney (Figure 2c). This exercise showed limited success - even though the data fit the model, the measures of fit were less significant, and the level of variation the substantive model described was lower. While the sampling techniques were the same and the risk characteristics of sample locations were similar (see section 3.3), the level of cohesiveness of the different communities was found to be considerably different. Low and Altman (1992) indicate that attachment to place (analogous to sense of community place in our study) often leads to the development of emotional bonds between community members. This in turn builds a sense of belonging not just to the location but also to the people living close by. The model validation (Figure 2a) suggested sense of community has a strong positive influence on wildfire preparedness, but this relationship was considerably weaker in the validation data from Hobart and Sydney collected during 2007/08.

Measurements of the social cohesion decision cues (sense of community people and collective problem solving) were lower amongst residents sampled in Sydney and Hobart in 2007/08. These lowered levels meant that the factors described less of the variation in the modelled preparedness data. This was particularly evident in the Sydney sample (Figure 2c). This may be an artefact of greater community heterogeneity within suburban Sydney, where the larger city supports greater diversity in culture, and the attitudes, beliefs and experiences 
Prior, T. \& Eriksen, C. 2013. "Wildfire preparedness, community cohesion and social-ecological systems." Global Environmental Change, Available online 31 October 2013. http://dx.doi.org/10.1016/j.gloenvcha.2013.09.016.

491

492

493

494

495

496

497

498

499

500

501

502

503

504

505

506

507

508

509

510

511

512

513

514

515

516

517

518

519

520

521

522

523

this diversity brings. This contention is supported by Wirth's (1969) theory of urbanism that suggests that increased size, density and heterogeneity in urban populations result in a fragmentation of social ties. Alesina and La Ferrera (2000) also highlight that greater diversity in the community leads to lower group participation and less-active social networks based within a locality. Instead, householders in these heterogeneous localities develop and often rely on social networks outside of their suburbs that do not form around a place-based issue like wildfire threat (Forrest and Kearns, 2001; Morrison, 2003). In Sydney, where social cohesion was not a strong feature of the studied communities, wildfire preparation was both less likely and considered less important. This was even the case among community members living in suburbs that had suffered previous catastrophic impacts from wildfire in 1994, but with no collective memory of either the wildfire or the associated deaths. The surveying in Sydney was undertaken in suburbs where the New South Wales Fire Brigades had placed 'community fire units' (a trailer with equipment to defend against a wildfire), and while these communities have benefited from these resources, they did not seem to have increased the level of community cohesion in these suburbs.

\subsection{Social cohesion, vulnerability and resilience in the natural hazards context}

The results presented here indicate that social cohesion plays a central role in wildfire preparation. The ability to enact preparations (cognitive, social and structural protective behaviours) is supported directly by the various 'elements' that contribute to social cohesion. The adaptive capacity these elements confer can increase resilience and can reduce specific wildfire vulnerabilities by mitigating exposure, reducing sensitivity and increasing response capacity (Smit and Wandel, 2006; Gallopín, 2006). Sense of community and collective problem solving contribute to self-organisation and effective response to hazard risk. Social networks that establish in cohesive communities also permit knowledge transfer, influencing social learning that promotes the benefits of preparation (Eriksen and Prior, 2011). These social networks also allow network members to share issues, burdens and emotional responses to the hazard that assist the individual to respond to and recover from a hazard. "Adaptations are manifestations of adaptive capacity" and "the presence of a strong kinship network may increase adaptive capacity" because it permits access to resources and other factors that can increase coping, but which might otherwise be unavailable (Smit and Wandel, 2006, p 287). Community relationships in this study encouraged short-term wildfire adaptive capacities that become long-term adaptations through reinforced learning and the creation of social norms around activities that increase wildfire resilience. However, our findings also support Smit and Wandel's (2006, p. 288) suggestion that "the conditions that interact to shape exposures, sensitivities, adaptive capacities, and hence create needs and opportunities for adaptation, are community specific". Influencing these 'community-specific conditions' is undoubtedly a useful approach that will help to address intractable problems in social-ecological systems.

\section{Conclusion: the importance of social cohesion for meaningful action}

Many recent studies examining human behaviour in the context of natural hazards and risk communication indicate that the relationship between the interpretation of an issue and action on that issue is a very complicated one (for example, Eiser et al., 2012; McCaffrey et al., 2013). Media, word of mouth and formal 
Prior, T. \& Eriksen, C. 2013. "Wildfire preparedness, community cohesion and social-ecological systems." Global Environmental Change, Available online 31 October 2013.

http://dx.doi.org/10.1016/j.gloenvcha.2013.09.016.

527

528

529

530

531

532

533

534

535

536

537

538

539

540

541

542

543

544

545

546

547

548

549

550

551

552

553

554

555

556

557

558

559

560

561

562

563

communication all influence the way people think about the issues or risks they face in their daily lives, but action ultimately comes down to a matter of what is salient to the individual (and therefore the perceived necessity to act or not). The study presented in this paper illustrates that social cohesion increases peoples' propensity to undertake protective actions in the context of wildfire in two ways: 1) it gives people the support and resources necessary to confront wildfire risk; and 2) it increases the salience of wildfire threat. Finding ways to shift the community (and individual) salience of an issue by focussing attention on the way people interact with others from their communities (whether place- or interest-based) may be an effective way to influence individual decision-making, and contribute to addressing complicated environmental issues like climate change and natural hazard management through local action.

This study illustrates that a fundamental benefit of social cohesion is the psycho-social and material support it brings to local community members. This support influences attitudes, values and emotions about wildfire, and the salience of this environmental 'problem'. While such processes currently lie beyond the remit of most contemporary modes of environmental risk communication, our results align with Shinn and Toohey's (2003) view that inserting a focus on social cohesion or social interaction is imperative. For instance, sense of community fosters emotional belonging as well as belonging through shared knowledge among community members. These 'resources' positively influence risk and mitigation beliefs so that wildfire preparation becomes the norm in the community rather than the exception. Without these resources community and individual protective actions are likely to be less commonly undertaken, less organised or less effective.

Another aspect that influences local scale action to combat global environmental issues like climate change is the often inconceivable nature and scale of these problems. This leads to negative outcome expectancy, as consequences and solutions are perceived to be beyond the individual's control (Adger, 2003). Indeed, such issues are typically dealt with by national governments, international organisations (e.g. UNEP) and multinational institutions (e.g. IPCC). Although the 'think global, act local' slogan is widely applied, managers of climate change issues have often done the opposite because international actors are perceived to have the power to redress the huge issues society faces in the environment. However, as the empirical data from our study demonstrate, social cohesion at the community level can positively influence individuals' outcome expectancy and capacity for action. While international actors are important in coordinating responses to climate change, refocusing on individuals and empowering their local action through social processes at the community level may yield more success when it comes to developing adaptive capacity to the impact of climate change on wildfire and other natural hazards. This point is supported by the vast literature (referenced throughout this paper) on the benefits of community-based resource/environmental management over topdown activities.

Furthermore, Westley and colleagues (2002) note that differences between social and ecological systems (particularly in relation to the characterising dimensions of each) contribute to a lack of responsiveness of the social components to critical environmental signals. Figures 1 and 2a-2c indicate that this may be a result of less obvious and overt pressure on the social components of the social-ecological system to adapt or respond to ecological problems. However, when social SES components are directly threatened by environmental or 
Prior, T. \& Eriksen, C. 2013. "Wildfire preparedness, community cohesion and social-ecological systems." Global Environmental Change, Available online 31 October 2013.

http://dx.doi.org/10.1016/j.gloenvcha.2013.09.016.

564

565

566

567

568

569

570

571

572

573

574

575

576

577

578

579

580

581

582

ecological processes (like natural hazards), the necessity to respond and adapt is paramount and obvious.

Transferring lessons learnt from disaster studies on the responsiveness and adaptability of social components to environmental conditions or changes may therefore be valuable in countering abstraction and improving management of human-induced environmental problems like climate change.

This paper demonstrates how social cohesion, especially factors like sense of community and the ability of community members to solve the problems they face together, is a key component of wildfire preparedness and resilience. Social cohesion provides a useful frame from which to explore broader considerations about how society impacts environmental processes and how environmental processes impact social practices, because people at risk of wildfire must actively respond to changes in their environment or face serious disruption to their lives. A focus on social cohesion in mitigating chronic (rather than acute) stress and change may also be helpful in other social-ecological systems where the environment puts less overt or immediately felt pressure on social systems, despite being equally important to the social components of the system (e.g., loss of ecosystem services due to biodiversity loss, slow creeping changes in sea level, food security and phosphorus depletion). Establishing ways to build cohesion in communities that are components of stressed social-ecological systems is important, because without cohesion context-specific norms are not formed, information is less likely to be transferred, and skills are not communicated or passed on. Social cohesion facilitates the transfer of information that can influence the social construction of issues or problems. It raises the salience of these issues relative to other everyday considerations among the community members within the social-ecological system.

\section{References}

Adger, W.N. (2003) Social capital, collective action, and adaptation to climate change. Economic Geography 79, 387-404.

Adger, W.N. (2006) Vulnerability. Global Environmental Change 16, 268-281.

AFAC, (2010) Position Paper on Bushfires and Community Safety. Australasian Fire and Emergency Services Authorities Council, p. 21.

Alesina, A., La Ferrara, E. (2000) Participation in heterogeneous communities. Quarterly Journal of Economics 115, 847-904.

Anderson, J.C., Gerbing, D.W. (1988) Structural equation modeling in practice: A review and recommended two-step approach. Psychological Bulletin 103, 411-423.

Bandura, A. (1977) Self-efficacy: Toward a unifying theory of behavioral change. Psychological Review 84, 191215.

Bandura, A. (1986) Social Foundations of Thought and Action: A Social Cognitive Theory. Prentice-Hall, Englewood Cliffs, NJ.

Basili, M. (2006) A rational decision rule with extreme events. Risk Analysis 26, 1721-1728.

Bechara, A., Damasio, H., Tranel, D., Damasio, A.R. (1997) Deciding advantageously before knowing the advantageous strategy. Science 275, 1293-1295.

Berkes, F. (2007) Understanding uncertainty and reducing vulnerability: Lessons from resilience thinking. Natural Hazards 41, 283-295.

Bihari, M., Ryan, R. (2012) Influence of social capital on community preparedness for wildfires. Landscape and Urban Planning 106, 253-261.

Bishop, B., Paton, D., Syme, G., Nancarrow, B. (2000) Coping with environmental degradation: Salination as a community stressor. Network 12, 1-15.

Bonanno, G.A. (2005) Resilience in the face of potential trauma. Current Directions in Psychological Science 14, 135-138. 
Prior, T. \& Eriksen, C. 2013. "Wildfire preparedness, community cohesion and social-ecological systems." Global Environmental Change, Available online 31 October 2013.

http://dx.doi.org/10.1016/j.gloenvcha.2013.09.016.

Bradstock, R.A., Cohn, J.S., Gill, A.M., Bedward, M., Lucas, C. (2009) Prediction of the probability of large fires in the Sydney region of south-eastern Australia using fire weather. International Journal of Wildland Fire $18,932-943$.

Brenkert-Smith, H. (2010) Building bridges to fight fire: The role of informal social interactions in six Colorado wildland-urban interface communities. International Journal of Wildland Fire 19, 689-697.

Brenkert-Smith, H. (2011) Homeowners' Perspectives on the Parcel Approach to Wildland Fire Mitigation: The Role of Community Context in Two Colorado Communities. Journal of Forestry 109, 193-200.

Brenkert-Smith, H., Champ, P.A., Flores, N. (2006) Insights into wildfire mitigation decisions among wildlandurban interface residents. Society and Natural Resources 19, 759-768.

Buxton, M., Tieman, G., Bekessy, S., Budge, T., Mercer, D., Coote, M., \& Morcombe, J.-A. (2006). Change and Continuity in Peri-Urban Australia, State of the Peri-Urban Regions: A Review of the Literature. In Land \& Water Australia / Department of Environment and Heritage (Ed.), (pp. 336pp). Melbourne: RMIT University.

Byrne, B.M. (2001) Structural Equation Modeling with AMOS: Basic Concepts, Applications and Programming. Psychology Press.

Carroll, M.S., Cohn, P.J., Seesholtz, D.N., Higgins, L.L. (2005) Fire as a Galvanising and Fragmenting Influence on Communities: The Case of the Rodeo-Chediski Fire. Society and Natural Resources 18, 301-320.

Carver, C.S., Scheier, M.F., Weintraub, J.K. (1989) Assessing Coping Strategies: a theoretically based approach. Journal of Personality and Social Psychology 56, 267-283.

CDRSS, (2006) Facing Hazards and Disasters: Understanding Human Dimensions, in: Committee on Disaster Research in the Social Sciences: Future Challenges and Opportunities, N.R.C. (Ed.). The National Academies Press, Washington D.C.

Cocklin, C., Dibden, J., (2005) Sustainability and change in rural Australia. University of New South Wales, Sydney.

Collins, T.W. (2009) Influences on wildfire hazard exposure in Arizona's high country. Society and Natural Resources 22, 211-229.

Cottrell, A. (2005) Communities and bushfire hazard in Australia: More questions than answers. Environmental Hazards 6, 109-114.

Cutter, S.L., Barnes, L., Berry, M., Burton, C., Evans, E., Tate, E., Webb, J. (2008) A place-based model for understanding community resilience to natural disasters. Global Environmental Change 18, 598-606.

Dake, K. (1992) Myths of Nature: Culture and the social construction of risk. Journal of Social Issues 48, 21-37.

Donovan, J.L., Blake, D.R. (1992) Patient non-compliance: Deviance or reasoned decision-making? Social Science and Medicine 34, 507-513.

Eiser, R.J., Bostrom, A., Burton, I., Johnston, D.M., McClure, J., Paton, D., van der Pligt, J., White, M.P. (2012) Risk interpretation and action: A conceptual framework for responses to natural hazards. International Journal of Disaster Risk Reduction 1, 5-16. http://dx.doi.org/10.1016/j.ijdrr.2012.05.002

Enarson, E. 2012. Women Confronting Natural Disaster: From Vulnerability to Resilience. Boulder, Colorado: Lynne Rienner Publishers, Inc.

Eng, E., Parker, E. (1994) Measuring community competence in the Mississippi Delta: The interface between program evaluation and empowerment. Health Education Quarterly 21, 199-220.

Eriksen, C., Gill, N. (2010) Bushfire and everyday life: Examining the awareness-action 'gap' in changing rural landscapes. Geoforum 41, 814-825.

Eriksen, C., Gill, N., Head, L. (2010) "The Gendered Dimensions of Bushfire in Changing Rural Landscapes in Australia." Journal of Rural Studies 26 (4):332-342

Eriksen, C., Prior, T. (2011) The art of learning: wildfire, amenity migration and local environmental knowledge. International Journal of Wildland Fire 20, 612-624.

Finucane, M.L., Alhakami, A., Slovic, P., Johnson, S.M. (2000) The affect heuristic in judgments of risks and benefits. Journal of Behavioral Decision Making 13, 1-17.

Folke, C. (2006) Resilience: The emergence of a perspective for social-ecological systems analyses. Global Environmental Change 16, 253-267.

Forrest, R., Kearns, A. (2001) Social cohesion, social capital and the neighbourhood. Urban Studies 38, 21252143.

Fox, C.R., Levav, J. (2000) Familiarity Bias and Belief Reversal in Relative Likelihood Judgment. Organizational Behavior and Human Decision Processes 82, 268-292.

Gallopín, G.C. (2006) Linkages between vulnerability, resilience, and adaptive capacity. Global Environmental Change 16, 293-303. 
Prior, T. \& Eriksen, C. 2013. "Wildfire preparedness, community cohesion and social-ecological systems." Global Environmental Change, Available online 31 October 2013.

http://dx.doi.org/10.1016/j.gloenvcha.2013.09.016.

664

665

666

667

668

669

670

671

672

673

674

675

676

677

678

679

680

681

682

683

684

685

686

687

688

689

690

691

692

693

694

695

696

697

698

699

700

701

702

703

704

705

706

707

708

709

710

711

712

713

714

715

716

Grothmann, T., Reusswig, F. (2006) People at risk of flooding: Why some residents take precautionary action while others do not. Natural Hazards 38, 101-120.

Gibbons, P., Van Bommel, L., Gill, A.M., Cary, G.J., Driscoll, D.A., Bradstock, R.A., Knight, E., Moritz, M.A., Stephens, S.L., and Lindenmayer, D.B. (2012) Land management practices associated with house loss in wildfires. PLoS ONE, 7 (1): e29212.

Haimes, Y.Y. (2009) On the definition of resilience in systems. Risk Analysis 29, 498-501.

Handmer, J., Haynes, K. (eds) 2008: Community Bushfire Safety, CSIRO Publishing, Collingwood.

Hannigan, A.J. (2006) Environmental Sociology: A Social Constructionist Perspective, 2nd ed. Routledge, London.

Hardin, C.D., Higgins, E.T., (1996) Shared reality: how social verification makes the subjective objective, in: Sorrentino, R.M., Higgins, E.T. (Eds.), Motivation and Cognition. The Guildford Press, New York, NY.

Hennessy, K., Lucas, C., Nicholls, N., Bathols, J., Suppiah, R., Ricketts, J., (2005) Climate change impacts on fireweather in south-east Australia. CSIRO Marine and Atmospheric Research and Australian Government Bureau of Meteorology, Melbourne, p. 88.

Holstein, J.A., Miller, G., (2006) Reconsidering Social Constructionism: Debates in Social Problem Theory. Aldine Transaction, New York, p. 560.

Jones, B.D. (1999) Bounded rationality. Annual Review of Political Science 2, 297-321.

Jonientz-Trisler, C., Simmons, R.S., Yanagi, B.S., Crawford, G.L., Darienzo, M., Eisner, R.K., Petty, E., Priest, G.R. (2005) Planning for Tsunami-Resilient Communities. Natural Hazards 35, 121-139.

Kahneman, D. (2003) A Perspective on Judgment and Choice: Mapping Bounded Rationality. American Psychologist 58, 697-720.

Keller, C., Siegrist, M., Gutscher, H. (2006) The Role of the Affect and Availability Heuristics in Risk Communication. Risk Analysis 26, 631-639.

Klein, R.J.T., Nicholls, R.J., Thomalla, F. (2003) Resilience to natural hazards: How useful is this concept? Environmental Hazards 5, 35-45.

Kline, R.B. (2011) Principles and Practices of Structural Equation Modeling, 2nd ed. The Guildford Press, New York.

Lachapelle, P.R., McCool, S.F. (2012) The Role of Trust in Community Wildland Fire Protection Planning. Society and Natural Resources 25, 321-335.

Lindell, M.K., Perry, R.W. (2000) Household Adjustment to Earthquake Hazard: A Review of Research. Environment and Behaviour 32, 461-501.

Lion, R., Meertens, R.M., Bot, I. (2002) Priorities in information desire about unknown risks. Risk Analysis 22, 765-776.

Loewenstein, G.F., Hsee, C.K., Weber, E.U., Welch, N. (2001) Risk as Feelings. Psychological Bulletin 127, 267286.

Low, S.M., Altman, I., (1992) Place attachment: A conceptual inquiry, in: Altman, I., Low, S.M. (Eds.), Place Attachment. Plenum Press, New York.

Lucas, C., Hennessy, K., Mills, G., Bathols, J., (2007) Bushfire weather in Southeast Australia: recent trends and projected climate change impacts. Bushfire Cooperative Research Centre, Melbourne, p. 84.

Lupton, D., Tulloch, J. (2002) Risk is Part of Your Life': Risk Epistemologies among a Group of Australians. Sociology 36, 317-334.

McCaffrey, S.M., Rhodes, A. (2009) Public response to wildfire: Is the Australian "stay and defend or leave early" approach an option for wildfire management in the United States? Journal of Forestry 107, 915.

McCaffrey, S.M., Stidham, M., Toman, E., Shindler, B. (2011) Outreach programs, peer pressure, and common sense: What motivates homeowners to mitigate wildfire risk? Environmental Management 48, 475 488.

McCaffrey, S., Toman, E., Stidham, M., Shindler, B. (2013) Social science research related to wildfire management: an overview of recent findings and future research needs. International Journal of Wildland Fire 22, 15-24. http://dx.doi.org/10.1071/WF11115.

McKenzie, D., Gedalof, Z., Peterson, D.L., Mote, P. (2004) Climatic change, wildfire, and conservation. Conservation Biology 18, 890-902.

McMillan, D.W., Chavis, D.M. (1986) Sense of community: A definition and theory. Journal of Community Psychology 14, 6-23.

Nachtigall, C., Kroehne, U., Funke, F., Steyer, R. (2003) (Why) Should We Use SEM? Pros and cons of structural equation modeling. Methods of Psychological Research Online 8, 1-22. 
Prior, T. \& Eriksen, C. 2013. "Wildfire preparedness, community cohesion and social-ecological systems." Global Environmental Change, Available online 31 October 2013.

http://dx.doi.org/10.1016/j.gloenvcha.2013.09.016.

Norris, F.H., Stevens, S.P., Pfefferbaum, B., Wyche, K.F., Pfefferbaum, R.L. (2008) Community resilience as a metaphor, theory, set of capacities, and strategy for disaster readiness. American Journal of Community Psychology 41, 127-150.

Paton, D., (2006) Disaster Resilience: Integrating individual, community, institutional and environmental perspectives., in: Paton, D., Johnston, D. (Eds.), Disaster Resilience: An Integrated Approach. Charles C. Thomas, Springfield, III.

Paton, D., Kelly, G., Bürgelt, P.T., Doherty, M. (2006b) Preparing for Bushfires: Understanding Intentions. Disaster Prevention and Management 15, 566-575.

Paton, D., Bürgelt, P., Prior, T. (2008) Living with bushfire risk: Social and environmental influences on preparedness. Australian Journal of Emergency Management 23, 41-48.

Paton, D., McClure, J., Bürgelt, P.T., (2006a) Natural Hazard Resilience: The role of individual and household preparedness., in: Paton, D., Johnston, D. (Eds.), Disaster Resilience: An Integrated Approach. Charles C. Thomas Ltd., Springfield, Illinois., p. 321.

Paveglio, T.B., Carroll, M.S., Absher, J., Robinson, W. (2011) Symbolic meanings of wildland fire: A study of residents in the U.S. Inland Northwest. Society and Natural Resources 24, 18-33.

Paveglio, T.B., Jakes, P.J., Carroll, M.S., Williams, D.R. (2009) Understanding social complexity within the wildland-urban interface: A new species of human habitation? Environmental Management 43, 1085 1095.

Prior, T., (2010) Householder bushfire preparation: decisionmaking and the implications for risk communication., School of Psychology. University of Tasmania, Hobart, Australia, p. 317.

Sheeran, P., (2002) Intention-behaviour relations: A conceptual and empirical review., in: Stroebe, W., Hewstone, M. (Eds.), European review of social psychology. Wiley, Chichester, England, pp. 1-36.

Shinn, M., Toohey, S.M. (2003) Community Contexts of Human Welfare. Annual Review of Psychology 54, $427-$ 459.

Siegrist, M., Cvetkovich, G. (2000) Perception of hazards: The role of social trust and knowledge. Risk Analysis 20, 713-719.

Siegrist, M., Gutscher, H. (2006) Flooding Risks: A Comparison of Lay People's Perceptions and Expert's Assessments in Switzerland. Risk Analysis 26, 971-979.

Siegrist, M., Gutscher, H. (2008) Natural hazards and motivation for mitigation behavior: People cannot predict the affect evoked by a severe flood. Risk Analysis 28, 771-778.

Sjöberg, L. (1982) Aided and Unaided Decision Making: Improving Intuitive Judgement. Journal of Forecasting 1, 349-363.

Slovic, P., Finucane, M.L., Peters, E., MacGregor, D.G. (2004) Risk as Analysis and Risk as Feelings: Some Thoughts About Affect, Reason, Risk and Rationality. Risk Analysis 24, 311-322.

Smit, B., Wandel, J. (2006) Adaptation, adaptive capacity and vulnerability. Global Environmental Change 16, 282-292.

Steelman, T.A., Kunkel, G.F. (2004) Effective Community Responses to Wildfire Threats: Lessons from New Mexico. Society and Natural Resources 17, 679-699.

Stewart, S. I., V. C. Radeloff, B. H. Roger, and J. H. Todd. (2007) Defining the wildland-urban interface. Journal of Forestry 105, 201-207.

Strauss, A.L., Corbin, J.M. (1990) Basics of qualitative research. Sage Publications, Newbury Park, California.

Strauss, A.L., Corbin, J.M. (1998) Basics of qualitative research : techniques and procedures for developing grounded theory, 2nd Edition ed. Sage Publications, Thousand Oaks.

Strunz, S. (2012) Is conceptual vagueness an asset? Arguments from philosophy of science applied to the concept of resilience. Ecological Economics.

Sturtevant, V., McCaffrey, S., (2007) Encouraging wildland fire preparedness: Lessons learned from three wildfire education programs, in: McCaffrey, S. (Ed.), The public and wildland fire management: Social science findings for managers. US Forest Service, Northern Research Station, Newtown Square, PA, pp. 125-136.

Thomalla, F., Downing, T., Spanger-Siegfried, E., Han, G., Rockström, J. (2006) Reducing hazard vulnerability: Towards a common approach between disaster risk reduction and climate adaptation. Disasters 30 , $39-48$.

Tierney, K.J. (1999) Toward a Critical Sociology of Risk. Sociological Forum 14, 215-242.

Tobin, G.A., Whiteford, L.M. (2002) Community Resilience and Volcano Hazard: The Eruption of Tungurahua and the Evacuation of the Faldas in Ecuador. Disasters 26, 28-48.

Tversky, A., Kahneman, D. (1974) Judgment under uncertainty: heuristics and biases. Biases in judgments reveal some heuristics of thinking under uncertainty. Science $185,1124-1131$. 
Prior, T. \& Eriksen, C. 2013. "Wildfire preparedness, community cohesion and social-ecological systems." Global Environmental Change, Available online 31 October 2013.

http://dx.doi.org/10.1016/j.gloenvcha.2013.09.016.

Tversky, A., Kahneman, D. (1981) The framing of decisions and the psychology of choice. Science 211, 453-458.

UN/ISDR, (2004) Living with Risk: A Global Review of Disaster Reduction Initiatives. United Nations, Geneva, Switzerland.

Ungar, M., (2012) Social Ecologies and Their Contribution to Resilience, in: Ungar, M. (Ed.), The Social Ecology of Resilience: A Handbook of Theory and Practice. Springer Science+Business Media, New York, pp. 1331.

Vermaak, J., van Niekerk, D. (2004) Disaster Risk Reduction Initiatives in South Africa. Development Southern Africa 21, 555-574.

Walker, B., Holling, C.S., Carpenter, S.R., Kinzig, A. (2004) Resilience, adaptability and transformability in socialecological systems. Ecology and society 9.

Walker, J., Cooper, M. (2011) Genealogies of resilience: From systems ecology to the political economy of crisis adaptation. Security Dialogue 42, 143-160.

Westley, F., Carpenter, S.R., Brock, W.A., Holling, C.S., Gunderson, L., (2002) Why Systems of People and Nature are not just Social and Ecological Systems, in: Gunderson, L., Holling, C.S. (Eds.), Panarchy: Understanding Transformations in Human and Natural Systems. Island Press, USA.

Whittaker, J., Handmer, J., Mercer, D. (2012) Vulnerability to bushfires in rural Australia: A case study from East Gippsland, Victoria. Journal of Rural Studies 28, 161-173.

Wildavsky, A., Dake, K. (1990) Theories of Risk Perception: Who Fears What and Why? Daedalus 119, 41-60.

Winter, G., Fried, J.S. (2000) Homeowner Perspectives on Fire Hazard, Responsibility, and Management Strategies at the Wildland-Urban Interface. Society and Natural Resources 13, 33-49.

Wirth, L., (1969) Urbanism as a way of life, in: Sennet, R. (Ed.), Classic Essays on the Culture of Cities. AppletonCentury-Crofts, New York. 